\title{
EDITORIAL
}

Xiaohong CHEN, Jinnan WANG, Shenggang REN

\section{Special issue: Resource-saving and environment-friendly (two oriented) engineering management and decision making}

\author{
(C) Higher Education Press 2019
}

Huang et al. reviewed the status and development of natural gas in the world's energy evolution, and pointed out that natural gas has become the primary energy source and the five dimensions of resource development, resource acquisition, trade system, infrastructure, and security system needs to be strengthened.

Zhao et al. showed that natural gas has become a transitional bridge from fossil energy to green and clean energy worldwide. Based on the potential of China's natural gas resources, production trends, supply and demand relationships, and gas supply safety factors, the future development of China's natural gas is predicted and solutions and recommendations are provided.

Chen pointed out that in the context of the integration of digital new technologies such as big data, the Internet of Things, artificial intelligence, blockchain, and virtual reality, smart cities have ushered in an era of forward-looking development. Smart cities have integrated new technologies to achieve practical innovations in government affairs, transportation, environmental protection, energy, medical care, and logistics. This has resulted in major social, economic, and ecological benefits, but some problems remain unsolved. Chen discussed the problems occurring during the development of smart cities, then proposed solutions and provided suggestions.

Lu et al. analyzed the connotation, function, and characteristics of intelligent construction of railway engineering and established a system structure that considers three dimensions of life cycle, layers of management, and intelligent function. In addition, seven key technical support systems of intelligent construction of railway engineering were established. The results show that a technical support system of intelligent construction of railway engineering has emerged in China, basic technology research is being conducted and preliminary applications have been developed.

Liu et al. pointed out that the core of China's low carbon development includes industrial structure optimization, clean energy technology, emission reduction technology, and institutional innovation. As a state-owned enterprise in

Received September 12, 2019

Xiaohong CHEN (囚)

Institute of Big Data and Internet Innovation, Hunan University of Technology and Business, Changsha 410205, China; Business School, Central South University, Changsha 410083, China

E-mail: csu_cxh@163.com

Jinnan WANG $(\bowtie)$

Chinese Academy of Engineering, Beijing 100088, China

E-mail: wanjn@caep.org.cn

Shenggang REN (ه)

Central South University, Changsha 410083, China

E-mail: 13875856216@163.com 
the energy industry, PetroChina has been actively involved in the development of a low-carbon economy, shouldering the responsibility of ensuring oil and gas supply, saving energy, and reducing emissions. The key technologies and equipment related to the development of green low-carbon petroleum engineering are described and suggestions are put forward.

Zhang et al. established an analytical framework for a cost-benefit analysis of the "Air Plan" in China. For the "Air Plan", 21 measures in seven policy areas were investigated, including adjustments of the structure and layout of industries, clean use of energy, industrial pollution control, boiler retrofitting and control, non-point source pollution control, motor vehicle pollution control, and regulatory capacity building. The costs and benefits of the implementation of the "Air Plan" in 30 cities and provinces in China from 2013-2017 were evaluated. The results showed that the total cost of implementation of the "Air Plan" was 1.65 trillion yuan.

Kennedy and Philbin pointed out that significant advances in battery technology are creating a viable market space for battery-powered passenger cars, and climate change as well as concerns over reliable supplies of hydrocarbons can help people focus on electric cars. The article analyzes the technical economy of electric, hybrid, gasoline and diesel vehicles, showing that the complexity of the power supply, infrastructure requirements, and complete life cycle issues indicate that electric vehicles will have a place in the future.

Lockley et al. pointed out that geoengineering (deliberate climate modification) is a potential approach to limit anthropogenic global warming (AGW). Solar radiation management geoengineering (SRM) offers relatively inexpensive, rapid temperature control. The low cost leads to the risk of controversial unilateral intervention, namely, the "free driver" problem. Lockley et al. proposed a new model of distributed governance, namely unilateralism of symbiotic constraints: The power of each country is limited to its fraction of the maximum realistic intervention (e.g., pre-industrial temperature). It is also recommended to divide authority based on historical emissions, i.e., a focus on alternatives (such as population). To provide a better understanding, a simulation of an overheated train carriage whose windows are controlled by passengers was conducted.

Zhang explored the dialectical relationship between energy and mineral resources development and the red line of ecological protection from the perspective of philosophy. The author suggested that the development of energy and mineral resources should be guided by the development of an ecological civilization, that is, the rational development of energy and mineral resources while protecting the environment. Zhang analyzed the impact of energy and mineral resources development on the ecological environment and listed the factors that govern the red-line mining rights of ecological protection according to the law in order to reduce the impact of mineral resources development on the environment.

Li et al. focused on the impact of CEO characteristics on environmental information disclosure in the annual report of listed companies on the Stock Exchange of Thailand. Regression analysis was used to explore the relationship between CEO characteristics and corporate environmental information disclosure in pollution-intensive enterprises. The results showed that the CEO's financial expertise, education level, and tenure were positively related to corporate environmental information disclosure. In contrast, the CEO's age or gender had no significant relationship with environmental disclosures.

$\mathrm{Hu}$ et al. explained the interest-related decision-making behavior of watershed ecological compensation by applying evolutionary game theory and establishing an evolutionary game model with a "reward and punishment" mechanism. The water quality data of the Xiangjiang River Basin were used to calculate the reward and punishment costs of different intervals by establishing a parametric regression model and local linear regression.

In the column of "Comments", Lin introduced the linkage mechanism between urban intelligence and low-carbon innovation, pointing out that low-carbon innovation is the industrial basis and source of energy power for urban intelligent development. The two should promote each other, support each other, and develop together.

In the column of "Super Engineering", He briefly and comprehensively introduced research on Xinjiang's energybased desert management strategy, which is a project that integrates global innovation concepts and innovative technologies.

This special issue on Frontiers of Engineering Management is an important step in the development of theory and 
methods for resource and environmental engineering management and decision. We believe that these studies will provide inspiring insights into the complexity and diversity of resource and environmental engineering management and decision-making research. Finally, we would like to thank all the authors for their valuable research on this special issue. We also sincerely thank the editors-in-chief and all staff for their supports during the organization and review of this special issue.

\section{Guest Editors-in-Chief}

\section{Xiaohong CHEN \\ Jinnan WANG Shenggang REN}

\author{
Hunan University of Technology and Business, China \\ Chinese Academy of Engineering, China \\ Central South University, China
}

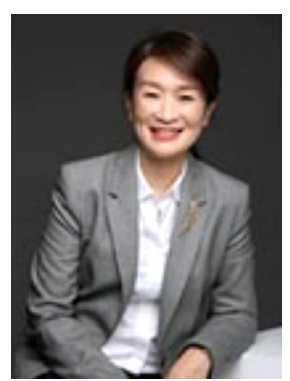

Xiaohong CHEN is an academician at the Chinese Academy of Engineering and an expert on management science and engineering. At present, she is the president of Hunan University of Technology and Business. She is also a winner of the "Outstanding Young Investigator Award" and a trans-century academic and technical leader of the national first- and second-level "Millions of Talents Project". She is the leading personnel of the "Millions of Plan" philosophy and social sciences of the Central Organization Department, and a member of the State Council Business Administration Discipline Review Group, the Management Department of the Ministry of Education, and the Social Science and Technology Commission. She has been recognized as a National Excellent Teacher, a National March Eighth Red Banner Holder, and the first outstanding social scientist in China. She is the leader of the innovative research group of the National Natural Science Foundation of China, and a member of the "Changjiang Scholar Innovation Team" of the Ministry of Education and the National Teaching Team.

She has presided more than 30 major national projects and successfully established China's first development platform of the decision-making application software for the development and utilization of metal mineral resources with independent intellectual property rights. She also won the following prizes: the second prize of the National Science and Technology Progress Award; one first prize and two second prizes for outstanding achievements in humanities and social sciences of the Ministry of Education, respectively; one first prize and one second prize of Hunan Guangzhao Science and Technology Award and Hunan Science and Technology Progress Award, respectively; and 14 research awards at the provincial and ministerial levels.

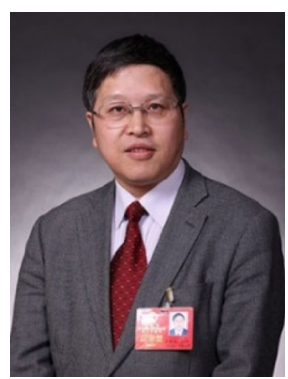

Jinnan WANG is an academician at the Chinese Academy of Engineering. He is the current dean of the Environmental Planning Institute of the Ministry of Ecology and Environment, the director of the National Key Laboratory of Environmental Planning and Policy Simulation, and a doctoral tutor. He has served as one of the six special group experts in the national air pollution cause and control, the chairman of the Global China Environmental Experts Association, the vice-chairman of the Chinese Society of Environmental Sciences, the deputy director of the National Eco-Environmental Expert Committee, and a senior consultant of the International Natural Resources Committee. He is also the deputy director of the Environmental Science and Engineering Professional Steering Committee of the Ministry of Education and the National Environmental Damage Assessment and Evaluation Expert Committee. He is an editor of eight magazines, including China Environmental Management.

He has published more than 300 papers and 11 monographs, such as Environmental Planning and Environmental Economics. He is the first candidate of national "Key Talent Project" and receives special government allowances from the State Council. He is also a direct liaison expert for the Central Committee of the Communist Party of China. $\mathrm{He}$ also received the Youth Science and Technology Award, Green China People's Special Award, National Excellent Science and Technology Worker, Earth (Sweden) Award, National Environmental Science and Technology Leader, and 22 national and ministerial science and technology awards. 


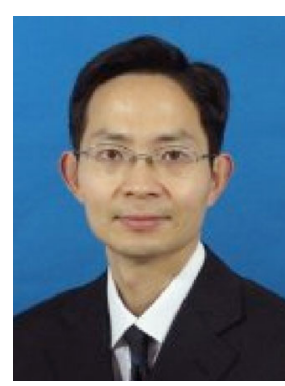

Shenggang REN is a professor and doctoral tutor at the Business School of Central South University. He is currently the party secretary of the Business School, a member of the academic committee of the school, and the director of the Humanities and Social Sciences Department. He graduated from Fudan University with a research direction in innovation management, industry, and environmental policy research. He received the Talents of the New Century of the Ministry of Education and served as the director of the Central Humanities and Social Sciences Key Base of Hunan Province. He is the chief expert of the National Social Science Major Project, the National Self-Sector Fund, the National Social Science Fund, and the government and enterprises.

He has published 2 academic works and more than 40 papers in international $\mathrm{SSCl}, \mathrm{SCl}$ journals. His research results won one first prize (ranked third) in the National Humanities and Social Sciences of the National University; two of his policy recommendations have been issued in the Outcome Report of the Central Propaganda Department and the Report of the Chinese Academy of Social Sciences; and three of the results have achieved provincial and ministerial levels. 